\title{
Land Use-Land Cover Dynamics at the Metropolitan Fringe
}

\author{
Daniel Felsenstein, Michal Lichter, Eyal Ashbel, and A. Yair Grinberger
}

\begin{abstract}
Diverse pressures for change operate at the outer metropolitan fringe. This paper examines the spatial and temporal dynamics of change in this area. We set up a simple model that incorporates spatial and temporal dynamics of functional (land use) and structural (land cover) interactions. We posit that land use (development) changes the ecosystem functions at the edge of urban areas expressed in change in land cover. Additionally, the characteristics of land cover (forest, agriculture, bare soil, neighboring cover etc.) mutually influence the land use. We estimate a model where land values and land use are jointly determined while land use and land cover interact recursively. We use historical data, probability estimation and land use simulation to generate panel data of future patterns of land value, land use and land cover at the outer edge of the Tel Aviv metropolitan area for the period 1995-2023. The modeling system combines panel 2SLS (2-stage least squares) estimation to investigate land value-land use interactions. Land use-land cover dynamics are estimated using panel MNL (multi-nomial logit) estimation. Results of simple simulations of the probability of land cover change are presented. When coupled with an appropriate biodiversity model, this system could potentially be extended to forecasting other aspects of the environmental stress of metropolitan expansion, for example impacts on vegetation or ecological dynamics.
\end{abstract}

\section{Introduction}

Worldwide, the metropolitan fringe is under heavy development pressure and in a constant state of flux. It interfaces between the built and the natural environments and serves as the battleground on which land use conflicts are fought.

D. Felsenstein $(\varangle) \cdot$ M. Lichter • E. Ashbel • A.Y. Grinberger

Department of Geography, Hebrew University of Jerusalem, Mt Scopus, 91905 Jerusalem,

Israel

e-mail:msdfels@mscc.huji.ac.il; mlichter@gmail.com; eyal.ashbel@gmail.com;

solomonico@gmail.com

D. Malkinson et al. (eds.), Modeling of Land-Use and Ecological Dynamics, Cities and Nature, DOI 10.1007/978-3-642-40199-2_8, C Springer-Verlag Berlin Heidelberg 2013 
Unsurprisingly, much of the effort in the area of modeling urban development is focused on land use change in this area (Ravetz et al. 2013). Invariably, this interest centers on the way in which human agents (developers, households, firms, governments etc.) generate a market for land. Under conditions of supply and demand, a price structure emerges and the market clears at the metropolitan fringe. Human behavior creates land uses of different kinds and these further impact on the emergence of a price structure that re-impacts on human behavior. In this loop, land prices are created endogenously (Felsenstein and Ashbel 2010).

This picture however is only partial. This is because land use is intricately connected to land cover. For example, high density development (land use) may be related to a particular land cover such as bare soil, low residential development may be associated with forest land or natural vegetation and so on. Once we extend the casual loop from the effect of human behavior on land use to its effect on land cover, we are essentially looking at the way in which anthropogenic shocks impact biophysical and ecological processes. This extended loop however is also circular. Land cover such as forest land, plantations and orchards also make for the attractiveness of areas adding to their economic value. In addition it serves an ecological purpose that also has monetary value for example by removing air pollutants, mitigating micro-climates, absorbing rainfall and reducing run-off.

This paper explores these interactions in the context of the metropolitan fringe. We extend the human behavior-land use causality to the realm of land cover and look at the dynamic feedback links between them. Based on these connections, we first estimate the joint determination of land values and land use. Then, we progress to tracing the temporal and spatial impacts of anthropogenic disturbances on land cover at the urban edge, through the mediation of land use. We do not attempt to forecast land use or land cover change. Rather, we take these predictions as inputs for a model that causally traces the interactions between land values, use and cover.

The driver of this process of market formation is land values but in addition we add temporal dynamics in which agents of change learn over time and spatial dynamics in which agents affect their neighbors. Current land use modeling does not generally specify the role of land cover and is only recently showing an interest in spatial and temporal dynamics (Irwin 2010). The proposed model is grounded in human behavior and can be potentially extended to incorporate biophysical processes. We only look at land cover conversion and not modification (Alberti and Waddell 2000). Conversion refers to change form one land cover to another, for example, form forest cover to urbanized cover. Modification describes the process of changing conditions within a given cover type for example, from deciduous forest to evergreen. We focus on land conversion as this represents the most direct and stark change taking place at the metropolitan fringe. Our approach allows for simulations of change in land values, residential densities and land use in the metropolitan fringe and their ripple-through effects over time and space. While we only observe intra-metropolitan fringe interactions, we believe that the modest extension to land cover presented here has potential for generating new insights into the dynamics of urban development. For example, questions such as 'do high residential densities tend to develop on particular land surfaces?', 'does urban 
development over time tend to seek out better quality land as supply tightens?' and 'do agents of change tend to affect each other?' are all issues high on both the policy and praxis agendas.

\section{Literature Review: Land Use-Land Cover Modeling}

The complexity of land use-land cover interactions has led to many different analytical approaches to modeling these relationships. These range from statistical-econometric, through analytic (equilibrium-based) to simulation- driven (micro, cellular agent and multi-agent variants). The differences between these different modeling systems has been comprehensively reviewed elsewhere (Irwin 2010; Parker et al. 2003; van Schrojenstein Lantman et al. 2011). Perhaps the most salient issue in studying the land use-land cover nexus is the explicit treatment of feedback mechanisms inherent in this connection. Verburg (2006) has addressed this issue by outlining the most common forms of feedback. However, the notion becomes all the more important when looking at dynamics. A typical feedback mechanism links social and biophysical systems. Thus, land use (an anthropogenic system) can degrade land cover (a biophysical system) causing a change in future land use. In the dynamic variant of this feedback earlier land use $(t-1)$ affects contemporaneous land cover $(t)$ which in turn affects future land use $(t+1)$. Additionally, a second feedback can occur across space (Verburg 2006). This generally involves land use change at one scale (for example regional demand for housing) impacting of land cover at another scale (the uprooting of local orchards). Again, in a spatially dynamic setting the feedbacks need to be modeled as spatial dependence in that local land cover might be affected by regional land use but also by neighboring land use/cover (Verburg et al. 2004).

Typically, dynamic feedbacks can be incorporated by using dynamic simulation models. The dynamics of land use- land cover change are often modeled within the framework of existing micro- simulation models. In this context the UrbanSim model (Waddell and Ulfarson 2003) provides particularly fertile ground. Urban development through the agency of households firms and developers provides the key socio-economic pathway to change that finds expression in land use. Microsimulation models are particularly useful at generating patterns of land use change at a high level of spatial resolution and at providing estimates of other socioeconomic activities associated with land use change (such as change in population composition, land values etc.). When this framework is combined with patterns of land cover change, it takes but a small extension to estimate the probabilities of land cover transitions.

Empirical studies have shown the inter-relationships between particular land uses and land cover types, for example multi-family residences and impervious surfaces and single family residences and forest cover (Alberti 2005, 2008). The extension to land cover raises a series of issues relating to unchartered territory of urban development and ecological outcomes. This is because the biophysical 
properties of change to land cover have a host of tertiary effects on soil quality, land productivity, run off, sedimentation rates etc. These are not always considered as part of the anthropogenic footprint of urban development that is heavily focused on land consumption infrastructure congestion and pollution.

The land use-land cover relationship has been extended to incorporate reciprocal influences on the ecological environment. Alberti and Waddell (2000) sketch out how the UrbanSim land use forecasting system can be coupled with a biophysical model to estimate the impact of land cover change on hydrology and nutrient cycling. An empirical application of this integration relating to avian diversity is reported by Hepinstall et al. (2008). They use land use inputs from the UrbanSim model and land cover change simulations from Landsat data in order to predict changes in the composition of avian species in Washington State. Their work provides one of the few empirically operationalized models that takes land use-land cover models to the realm of ecological response within an integrated framework.

Dynamic simulation is undoubtedly pushing forward the frontiers of interdisciplinary work to understand the feedbacks between physical, economic and ecological change. Coupled with high resolution spatial and temporal data, efforts are no longer solely aimed at understanding landscape change as the outcome of a collective response to attain the highest and best use from land given bio-physical constraints. Rather, recent modeling tends to stress 'neighborhood' influences, idiosyncratic preferences, regulation and the influence of time. Together these make for a much more challenging modeling environment.

\section{A Conceptual Model}

We posit a particular causal sequence in the interactions between land use, land cover and human agency (Fig. 1). We use a bottom-up approach (Irwin et al. 2009) in which anthropogenic influences are assumed to generate a market for land and generate change in land use through the utility-maximizing activities of households, firms, land developers and policy makers. This in turn has a mutual effect on land values. The choice to convert a parcel of land to a different use or intensify current use is jointly determined with the expected return from that parcel. This simultaneity between land values and property prices on the one hand and other features of the land market such as regulatory practices (Ihlanfeldt 2007) and new construction (Mayer and Somerville 2000) is the subject of much attention in the urban economics and real estate literature. Land use and land cover are also posited to be causally related. We expect interactions to be recursive rather than simultaneous as temporal and spatial dynamics play a more pronounced role. Land use and land cover conversion are lengthy processes that do not react instantly to market signals (Verburg et al. 2004; Verburg 2006) and we thus assume a recursive process. The framework outlined in Fig. 1 can potentially be extended to incorporate more explicit ecological and biophysical inputs. If coupled with a biodiversity model 


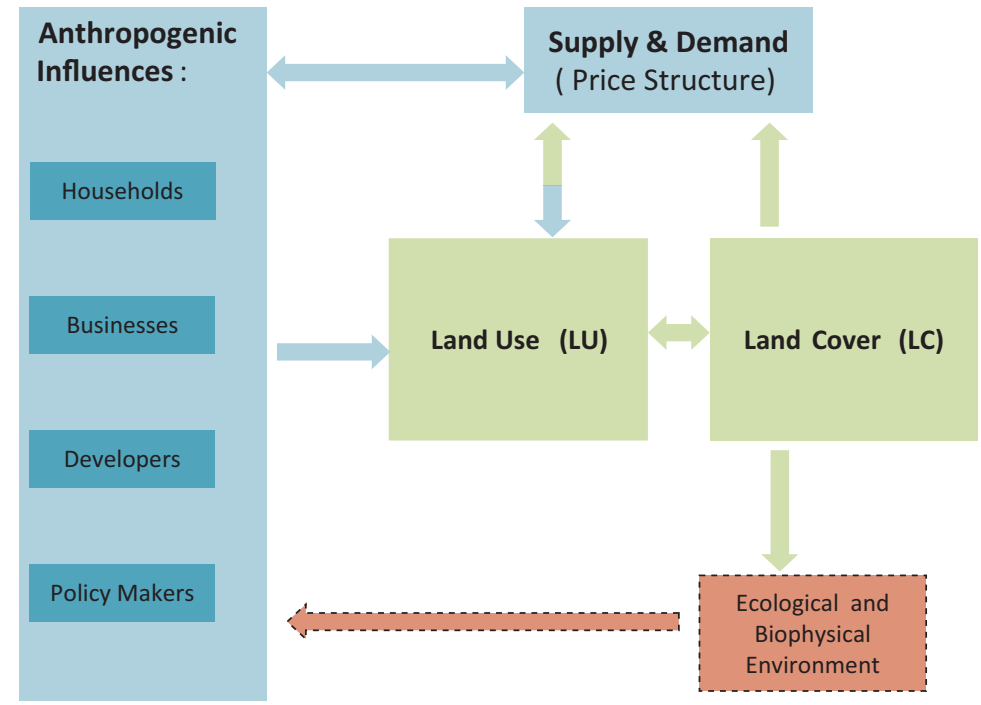

Fig. 1 Conceptual model

for example, the system would be capable of forecasting the environmental stress of metropolitan expansion on vegetation and ecological dynamics.

In line with classic models of urban structure, land value is expected to be directly related to residential density and gross number of units. It is expected to be inversely related to distance from the CBD and probably directly related to highway accessibility. Potential endogeneity exists of course between land values and residential density used here to represent land use. We expect land values to have a direct and positive effect on intensity of land use. In addition, temporally and spatially lagged residential densities are expected to have a similar effect on current land use density. Commercial activity is also posited to be directly related to residential land use intensity. Conversely, distance to the metropolitan center and to highways is expected to reduce pressure on residential density.

Land cover change consists of a set of spatially explicit choices relating to sitebased land cover transitions. The likelihood of a single unit (grid cell) changing from one discrete land cover class to another class is a function of temporally lagged land cover, land use and neighboring land use, that represent endogenous pressure and endogenous attributes of the unit such as distance from the metropolitan center or distance from central points of accessibility such as highways.

Land value (V) land use (U) in unit $i$ and time $t$ are co-determined (Felsenstein and Ashbel 2010) such that:

$$
V_{i t}=\lambda U_{i t}^{\prime}+\beta_{i t} X_{i t}+\varepsilon_{i t}
$$




$$
U_{i t}^{\prime}=\delta V_{i t}+\beta_{i t} \boldsymbol{X}_{i t}+v_{i t}
$$

where: $\lambda, \beta, \delta=$ parameters to be estimated, $\mathrm{U}^{\prime}=$ estimated land use, $\mathrm{X}=$ vector of cell (unit) attributes.

Interactions between land use and land cover (C) are captured through their spatial and temporal dynamics. Spatial dynamics represent the effect of change in neighboring units on the target unit. In the case of $\mathrm{U}$, this is expressed by the asterisked variable $U_{i t}^{*}$,

$$
U_{i t}=\alpha_{i}+\beta X_{i t}+\theta U_{i t}^{*}+u_{i t}
$$

where the spatial lag is generated by appropriate row-summed spatial weights $\left(w_{i j}\right)$.

$$
U_{i t}^{*}=\sum_{j \neq i}^{N} w_{i j} U_{j t}
$$

Temporal dynamics are expressed as the time lagged value of the target unit,

$$
U_{i t}=\alpha^{\prime}+\beta^{\prime} X_{i t}+\theta^{\prime} U_{i t-1}+u_{i t}
$$

While $\mathrm{U}$ is often measured as a discrete variable, we follow the tradition of observing land use as a continuous variable represented by the intensity of use of artificial surfaces (Alberti 2005; Lopez et al. 2001; Ravetz et al. 2013). Operationalizing $\mathrm{U}$ and $\mathrm{C}$ interactions we posit that $\mathrm{U}$ (residential density) is determined by $\mathrm{V}$, previous residential density and neighboring density (i.e. spatially and temporally lagged $\mathrm{U}$ ), the presence of commercial activity and various distance attributes (K), as follows:

$$
U_{i t}=\alpha U_{i t-1}+\lambda \sum_{i \neq n}^{N} w U_{i t}+\delta V_{i t}+K X_{i t}+v_{i t}
$$

Land cover (C) change is subsequently expected to be influenced by previous land cover, current $\left(U^{*}\right)$ and temporally lagged land use and a vector of distance measures:

$$
C_{i t}=\gamma C_{i t-1}+\alpha U_{i t-1}+\lambda U^{*}{ }_{i t}+K X_{i t}+u_{i t}
$$

With this system set up, scenario based simulations can be derived. Impulse response movements can be simulated to answer question such as how would an increase in current land value affect the likelihood of land cover change from bare soil to built area in the future, i.e. $\partial C_{t+1} / \partial V_{t}$ ? The matrix formulation and mathematical structure of the recursive estimation are presented in Appendix 1. 

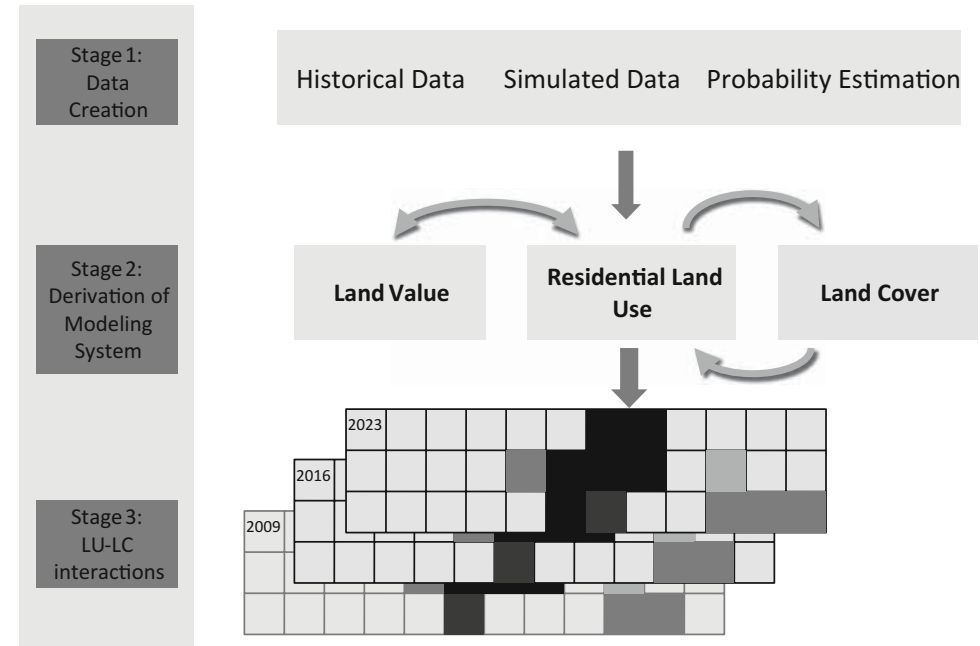

Fig. 2 Method

\section{Estimation Strategy}

The estimation strategy is outlined in Fig. 2. As the key issue here is the interaction between temporal and spatial dynamics and not land use/cover forecasting, we use opportunistic mix of historical, simulation and probability generated data on which to test our method. The nature of the data generation process is described below. Our main thrust is focused on deriving the estimation system and then generating some simple statistical simulations highlighting the interplay between land values, residential density (representing land use) and land cover. We are cognizant of the reservations associated with both econometric land use modeling coupled with spatial simulation (endogeneity) and raster GIS-based models (spatial dependence) (Irwin 2010). The estimation strategy adopted addresses these issues directly.

Our approach is based on the joint determination of land values and (residential) land use. This simultaneity raises the specter of endogeneity i.e. the notion that one or more of the explanatory variables of land value and use is jointly determined with the dependent variable, typically through an equilibrium mechanism. Simultaneity is a common issue in economic behavior. A key feature of simultaneous equations models such as supply-demand systems is that a change in either supply or demand will affect both the equilibrium price and quantity in the market, so that by construction both variables are correlated with any shock to the system. An explanatory variable that is determined simultaneously with the dependent variable is generally correlated with the error term. OLS estimation of such a model will produce biased and inconsistent estimators. In simultaneous equation systems such as ours, the common strategy is to identify the parameters using instrument variables (IV) and to estimate using two stage least squares (2SLS). As we use panel data, the panel 2SLS variant calls for first, eliminating unobserved 
effects by using first differencing and second, using IV's for the endogenous variables (Baltagi 2008). In stage 1 of the estimation models are fitted using all exogenous variables and the predicted values obtained. From these reduced-form estimates, predicted values from each model are obtained for use in Stage 2. In this stage the original endogenous variables from the first stage are replaced by their fitted values.

For investigating land use-land cover interactions we use probability estimation for multinomial responses. However given the structure of our data (a short panel data with many observations), maximum likelihood estimators may not be consistent or efficient due to the presence of the 'incidental parameter' issue (Neyman and Scott 1948). This occurs when a time-constant parameter that represents some innate feature of land cover (such as slope or porosity) varies across individuals units and may serve as a source of endogeneity in other $x_{i t}$ regressors. This limits probability estimation in panel data. In the multinomial case, Baltagi (2008) and Lee (2013) have suggested using a 'panel conditional' estimator. Given the existence of unobserved individual effects $\alpha_{i}$ that are time constant, along with $X_{i t}$ observed characteristics between individuals and over time, we follow Haan and Uhlendorff (2006) using a STATA routine for estimating an MNL model for land cover using panel data. In the regular MNL approach, the probability of making choice $j$ conditional on observed characteristics $X_{i t}$ and unobserved individual effects $\alpha_{i}$ is:

$$
\operatorname{Pr}\left(j \mid X_{i t} \alpha_{i}\right)=\frac{\exp \left(X_{i t} \beta_{j}+\alpha_{i j}\right)}{\sum_{k=1}^{J} \exp \left(X_{i t} \beta_{j}+\alpha_{i j}\right)}
$$

However as the choice probabilities are conditioned on $\alpha_{i}$, this requires integrating Eq. 1 on the distribution to get the likelihood (L) as follows:

$$
L=\prod_{i=1}^{N} \int_{-\infty}^{\infty} \prod_{t=1}^{T} \prod_{j=1}^{J}\left\{\frac{\exp \left(X_{i t} \beta_{j}+\alpha_{i j}\right)}{\sum_{k=1}^{J} \exp \left(X_{i t} \beta_{j}+\alpha_{i j}\right)} . .\right\}^{d_{i j t}} f(\alpha) d \alpha
$$

where $d_{i j t}=1$ if unit $i$ transitions to alternative $j$ at time $t$ and 0 otherwise. The coefficient vector and the unobserved heterogeneity term of one category are set to 0 for identification of the model. We assume that unobserved heterogeneity $\alpha$ is identically and independently distributed over all units and follows a multivariate normal distribution with mean $a$ and variance-covariance matrix $\mathbf{W}, \alpha \sim f(a, W)$.

The spatial nature of units (expected land cover in neighboring units) is considered a feature of $X_{i t}$. On the one hand, this obviates the need for estimating an enormous spatial weight matrix given the grid cell structure of the data (see below). On the other hand, it calls for appropriate treatment of spatial dependence between observations. While the routine way of dealing with this is via a row-summed weight matrix (see Eq. 3 above), this is obviously untenable in our case. Consequently we use a dedicated Python script to create spatial lags by automatically 
averaging the values of the eight neighboring cells around the target cell. It should be noted that while this approach technically generates values for 'neighbors', the real spatial lag is still not properly identified due to the circular 'I-am-my-neighbor's-neighbor' property of spatial relations.

\section{Data}

\subsection{Data Preparation}

In line with other studies of land use land cover interactions (Alberti 2005; Hepinstall et al. 2008) we exploit various sources in order to assemble the land use and land cover data. Our data set cover the period 1995-2023, so by construction we are using synthetic data. Land cover data for historical periods come from a compilation of different GIS data covers: 1995 data comes from the National Outline Plan (NOP) \#35, 2002 data from the central Bureau of Statistics (CBS) and 2009 data comes from the Survey of Israel. This spatial series is extended at 7 year lags through to 2023 using probability estimation as outlined in Appendix 2. This yields five basic land cover classes: urbanized (built area), bare soil, forests, orchards/plantations and fields. 'Urbanized areas' is a catch-all category that acts as the baseline and includes any grid cell where built structures or urbanized land cover such as parks and gardens form the majority footprint in the grid cell. For comparison, a remote sensing study of natural habitats in Israel used a similar schema based on bare soil, dunes, herbaceous trees, shrubs, agricultural cover and water bodies (Levin et al. 2011).

Land use relates to residential land use and is measured by residential intensity. Other metrics of land use that could have been used include land use heterogeneity and connectivity, but intensity is often used as the default choice (Alberti 2005). The source of this data and of all the other attributes of grid cells such as residential land value, residential units, non residential area etc. is the UrbanSim 3.0 model calibrated for the Tel Aviv metropolitan area (Felsenstein et al. 2007). The historical starting point for this data is 1995 and all subsequent periods relate to simulated data. The simulated data is generated at the $250 \times 250 \mathrm{~m}$ grid cell level. Given this source, the data consists of five balanced panels each with nearly 10,000 grid cells. The lack of symmetry between the temporal $(\mathrm{T}=5)$ and spatial $(\mathrm{N}=\sim 10,000)$ components of the data, should be noted. Despite this a-symmetry, the data was treated as a panel rather than pooled cross-section thereby utilizing all data fully. Obviously, this structure constrains the use of a spatial weight matrix and spatially lagged variables are constructed in a manner described above.

Table 1 describes the variables, their sources and the way they are constructed. 
Table 1 Variables, method of construction and sources

\begin{tabular}{|c|c|c|}
\hline Variable & Calculation method & Source \\
\hline Land cover 1995 & Raster to grid cells using zonal statistics & $\mathrm{NOP} / 35$ \\
\hline Land cover 2002 & Vector to grid cells using zonal statistics & CBS \\
\hline Land cover 2009 & Vector to grid cells using zonal statistics & Survey of Israel \\
\hline $\begin{array}{c}\text { Residential } \\
\text { density }\end{array}$ & $\begin{array}{l}\text { Gross residential unit density: number of resi- } \\
\text { dential units divided by grid cell area }\end{array}$ & $\mathrm{NOP} / 35$ \\
\hline Residential units & $\begin{array}{l}\text { Residential units allocated to grid cells with } \\
\text { centroids within the census tract. }\end{array}$ & 1995 National Census \\
\hline $\begin{array}{l}\text { Residential land } \\
\text { value }\end{array}$ & $\begin{array}{l}\text { Average value per sqm * residential footprint } \\
\text { sqm }\end{array}$ & $\begin{array}{l}\text { Israel Land } \\
\text { Administration-results } \\
\text { of land auctions }\end{array}$ \\
\hline $\begin{array}{l}\text { Nonresidential } \\
\text { land value }\end{array}$ & $\begin{array}{l}\text { Average value per sqm } * \text { non-residential foot- } \\
\text { print sqm }\end{array}$ & $\begin{array}{l}\text { Israel Land Administra- } \\
\text { tion -results of land } \\
\text { auctions }\end{array}$ \\
\hline $\begin{array}{l}\text { Non residential } \\
\text { area }\end{array}$ & area of the grid cell $*$ ( 1 -fraction residential land) & $\mathrm{NOP} / 35$ \\
\hline $\begin{array}{l}\text { Distance to } 1 \text { digit } \\
\text { highway }\end{array}$ & $\begin{array}{l}\text { Euclidean distance (sqm) from centroid of cell to } \\
\text { highway }\end{array}$ & MAPA 2009 \\
\hline $\begin{array}{l}\text { Distance to TLV } \\
\text { metropolitan } \\
\text { CBD }\end{array}$ & $\begin{array}{l}\text { Euclidean distance (sqm) from centroid of cell to } \\
\text { metropolitan core boundary (defined by CBS) }\end{array}$ & CBS \\
\hline
\end{tabular}

\subsection{Data Description}

The metropolitan fringe is a transitional area under urban influence but with rural morphology. We define this transitional zone as a $5 \mathrm{~km}$ buffer that starts at the outer boundary of the metropolitan area and extends inwards. The area contains some 154 municipal entities, 37 of them are urban municipalities and the rest, small communities and villages. The population of the fringe zone is 670,000 and average household income is nearly 18,000 sh (2008). The Tel Aviv metropolitan area (minus the urban fringe area) has a population of 2,630,000 and average household income similar to the fringe area.

Table 2 describes the main changes in key variables in the metropolitan fringe over the period 1995-2009 and compares these with corresponding changes in the metropolitan area. Most of the pressure for change stems from residential expansion in five growth points. The city of Ashdod increased its population by $63 \%$ from 126,000 in 1995 to 206,500 in 2009. Perhaps the most dramatic growth occurred in the area of Modiin where a new city was constructed and populated virtually ex nihilo over this period resulting in population growing from 10,600 in 1995 to 72,700 in 2009. The small town of Rosh Ha'ayin saw a $30 \%$ population increase from 29,000 to 38,000, the trio of small Arab towns (Tira, Taibe and Kalansua) experienced population growth of $40 \%$ (from 54,000 to 76,700) and the medium sized city of Kfar Saba saw the lowest rate of growth $(18 \%)$ with population expanding from 70,500 to 83,600. In all, these 5 growth poles account for over $70 \%$ of the entire population in the metropolitan fringe. 
Table 2 Land use and land cover changes in the metropolitan fringe, 1995 and 2009

\begin{tabular}{llllll}
\hline & 1995 & & & 2009 & \\
\cline { 2 - 3 } \cline { 5 - 6 } & Metro area & Fringe & & Metro area & Fringe \\
\hline Residential land value $^{\mathrm{a}}$ & 130,624 & 53,907 & & $3,402,274$ & $3,167,253$ \\
Residential units $^{\mathrm{b}}$ & 679.1 & 100.1 & & 868.3 & 207.5 \\
Non-resid land value $^{\mathrm{c}}$ & $3,896,467$ & $3,369,864$ & & $5,750,738$ & $5,606,086$ \\
Commercial area $^{\mathrm{d}}$ & 3.503 & 1.334 & & 24.546 & 14.921 \\
Land cover $^{\mathrm{e}}$ & & & & \\
Bare soil & 134.4 & 140.9 & & 129.8 & 210.0 \\
Forests & 40.1 & 34.5 & & 56.8 & 48.9 \\
Orchards & 141.5 & 93.3 & & 96.8 & 62.1 \\
Fields & 143.3 & 174.2 & & 183.4 & 131.9 \\
Urbanized area & 376.5 & 119.1 & & 424.6 & 165.1 \\
\hline
\end{tabular}

${ }^{a}$ Average value per grid cell (Israeli Shekels m, current prices)

${ }^{\mathrm{b}}$ Total residential units (th)

${ }^{\mathrm{c}}$ Average value per grid cell, commercial, industrial and governmental land uses (Israeli Shekels $\mathrm{m}$, current prices)

${ }^{\mathrm{d}}$ Total footprint area, m sq.m.

${ }^{\mathrm{e}}$ Total area, m sq.m.

The data in Table 2 reflect these dramatic changes. The gaps between the metropolitan area and the fringe in residential land values and number of units in 1995 are closed or equalized by 2009. Non residential land values are roughly similar in both periods whereas the share of increase in commercial areas (assumed to follow the growth of residential areas) is particularly pronounced in the fringe. In terms of land cover change, there is a dramatic increase in bare soil area in the fringe, often a precursor of land conversion. In the metropolitan area the amount of bare soil actually contracts. Forest cover also increases in both areas. However as this is generally due to public initiative it could be a knee-jerk reaction to development pressures in other parts of the fringe and an attempt to curtail development.

Table 3 highlights the urban fringe alone and presents simulated data out till 2023. The main feature of these data is the expected entrenchment of patterns started over the period 1995-2009. Residential units, densities and land values are expected to continue to grow unabated and to generate large increase in attendant commercial areas. With respect to land cover, forests (after an initial growth period) orchards and fields are all expected to contract. In contrast, the prevalence of bare soil (as an interim land cover) continues to expand and along with it urbanized land cover (buildings and other non-natural covers) is expected to increase.

Figures 3 and 4 depict the main changes expected in land use and land cover over the simulation period. For land use, we see the progression of increasing colonization and intensification over the period as residential densities increase in both scale and scope. Figure 3 highlights the example of Modiin where public sector-led development has initiated a process in the south east corner of the fringe area. The intensity of development is not forecast to rival that of the more established urban centers in the fringe but the scale of low intensity development is large. 
Table 3 Land values, use and cover in the metropolitan fringe, simulated data

\begin{tabular}{llllll}
\hline & 1995 & 2002 & 2009 & 2016 & 2023 \\
\hline Residential land value $^{\mathrm{a}}$ & 53.9 & $2,224.5$ & $3,166.8$ & $4,172.8$ & $4,768.8$ \\
Residential units $^{\mathrm{b}}$ & 100.1 & 158.2 & 207.5 & 271.3 & 324.3 \\
Residential density $^{\mathrm{c}}$ & 162 & 256 & 336 & 439 & 524 \\
Commercial area $^{\mathrm{d}}$ & 1.334 & 8.918 & 14.921 & 22.851 & 28.956 \\
Land cover $^{\mathrm{e}}$ & & & & & \\
Bare soil & 140.9 & 161.7 & 210.0 & 235.4 & 260.1 \\
Forests & 34.5 & 74.8 & 48.9 & 36.5 & 23.5 \\
Orchards & 93.3 & 92.0 & 62.1 & 57.5 & 50.5 \\
Fields & 174.2 & 183.4 & 131.9 & 119.1 & 91.2 \\
Urbanized area & 119.1 & 106.1 & 165.1 & 169.5 & 186.7 \\
\hline
\end{tabular}

${ }^{a}$ Average value per grid cell (Israeli Shekels m, current prices)

${ }^{\mathrm{b}}$ Total residential units (th)

${ }^{\mathrm{c}}$ Average units per sq $\mathrm{km}$

${ }^{\mathrm{d}}$ Total footprint area, m sq.m.

${ }^{\mathrm{e}}$ Total area, m sq.m

The land cover changes in Fig. 4 portray the spatial detail of the aggregate data in Table 3. The virtual disappearance of orchards and forests in the urban fringe by 2023 could not be discerned from data relating to the earlier periods (Fig. 4). Again focusing on the case of Modiin, we can note an upsurge of forest and field cover after the development of the area. This process has also been noted elsewhere (Levin et al. 2011) where initial urban encroachment into the fringe is characterized by an abrupt decrease in vegetative cover as land is stripped bare in preparation for urban expansion. After a period of time, the vegetation returns in the form of man-made land cover (parks, gardens and sculptured open spaces).

\section{Results}

\subsection{Estimation Results}

We employ statistical estimation and impulse response simulation. Equations 1, 5 and 6 are estimated as a system with spatial and temporal lags acting as the links. Impulse response shocks (simulations) are used to disturb the system and the perturbations are grounded in the spatial and temporal lag structures dictated by the model. Given the lattice structure of the spatial data, the results of the simulation are presented in map form.

The two-way causality and system feedbacks inherent in estimating Eqs. 1 and 2 above are a source of endogeneity. Land value is both driven by and drives residential density. We use panel 2 SLS to deal with this and specify instrument variables for each stage of the regression. As we use fixed effects, the $\mathrm{R}^{2}$ and constant in both the land value and the residential density models are very large 

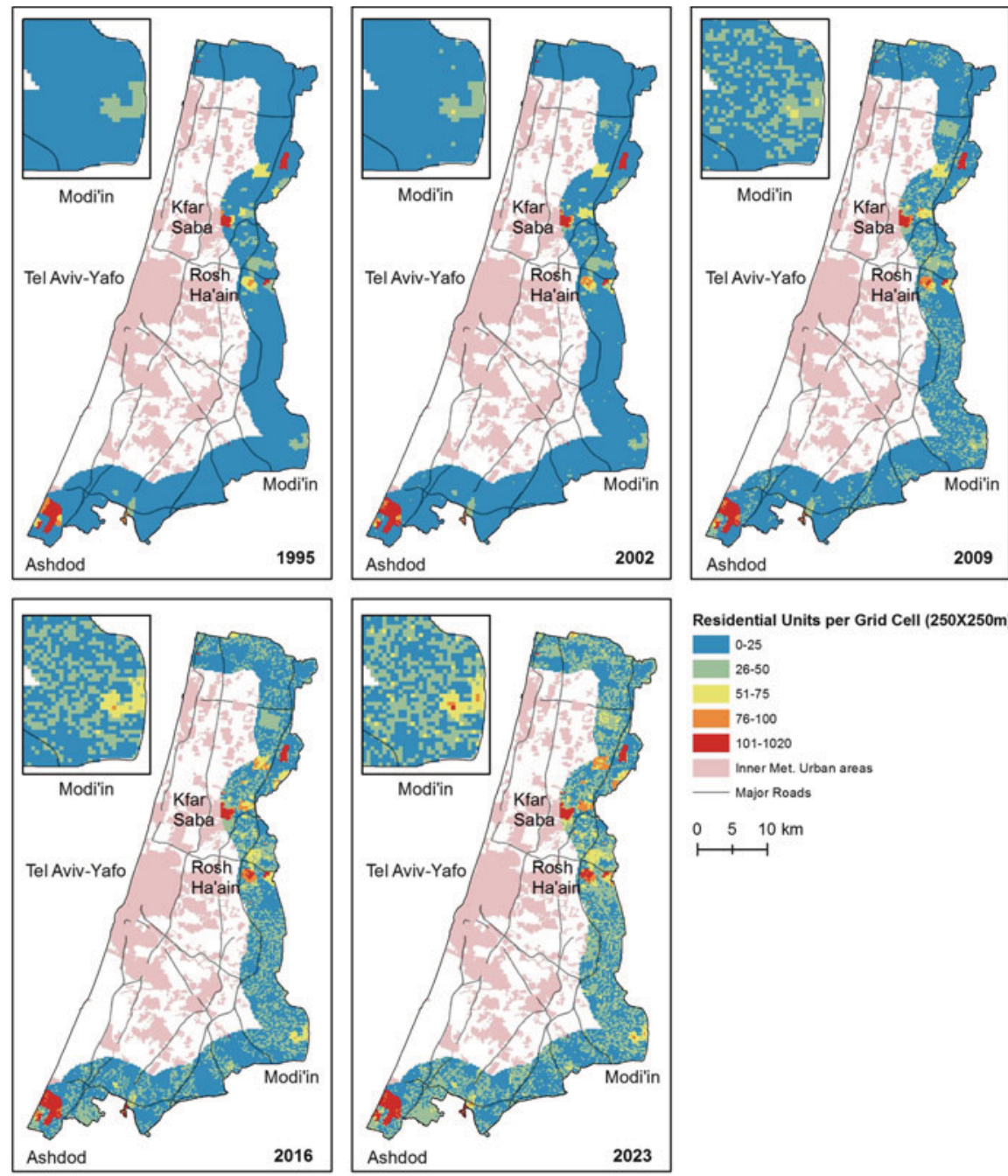

Residential Units per Grid Cell (250X250m)

0.25

26-50

$51-75$

76-100

101-1020

Inner Met. Urban areas

— Major Roads

$0 \quad 510 \mathrm{~km}$

Fig. 3 Land use change 1995-2023 in the metropolitan fringe

(Table 4). The latter indicates that there is much going on in the model that is not explained by the regressors. In the land value model units have the right sign but density is counter intuitive. The effects of distance (both centrality and accessibility) are inversely related to value and significant. In the land use model, land value again displays the opposite sign to that expected. Spatial (RD neighbors) and temporal (RD lag) effects of land use have a direct and positive effect on current land use. Commercial activity is also directly related while the distance measures display inverse signs as expected and distance to the CBD (centrality) is not significant. 

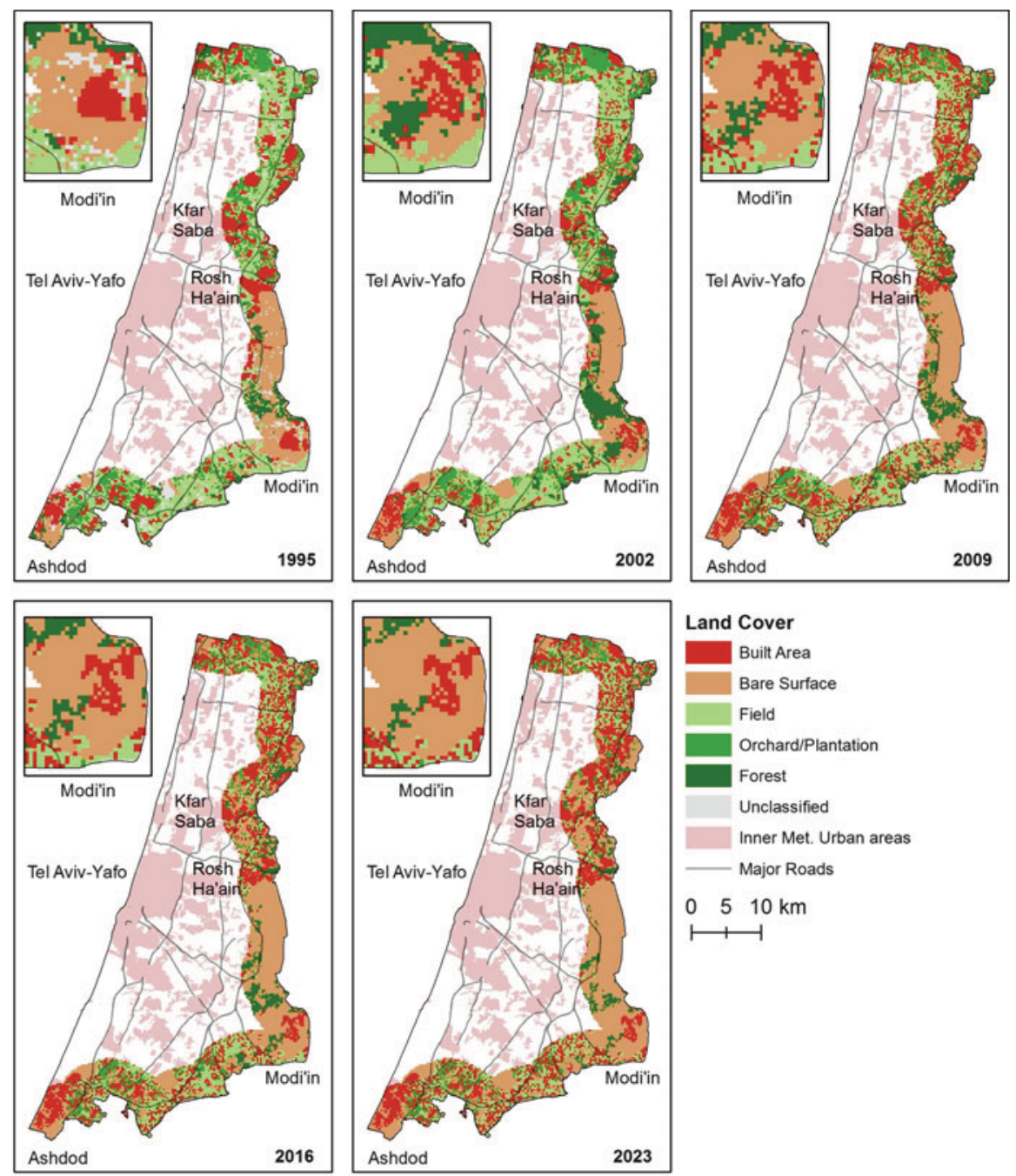

Fig. 4 Land cover change 1995-2023 in the metropolitan fringe

Table 5 shows the estimated results for Eqs. 5 and 6 using panel MNL regression. The recursivity in this estimation is through the current and lagged effect of land use. The coefficients in Table 5 need to be interpreted as the effect of a one unit increase in the regressor, on the relative log odds of the land cover (bare soil, forests etc.) transitioning to urbanized (the baseline category). For example, we can see that a unit change in residential density is associated with a 0.074 decrease in the probability of bare soil cover transitioning to urbanized. For three out of the four land covers an increase in residential density leads to a decrease in the chance of that land cover staying in its current state, but this result is only statistically 
Table 4 Panel 2SLS estimation of land values and residential density (with fixed effects)

\begin{tabular}{llll}
\hline Land value & \multicolumn{3}{c}{ Residential density } \\
\hline Constant & 83.016 & Constant & 25.586 \\
Resid density (RD) & -1.413 & Land value & -0.706 \\
Units & 1.181 & RD (lag) & -0.085 \\
Dist. h'way & -0.012 & RD (neighbors) & 0.061 \\
Dist CBD & -0.0007 & Commercial area & 0.215 \\
& & Dist h'way & -0.003 \\
& & Dist CBD & $-0.00023^{*}$ \\
Adj. R & & Adj. R & 0.946 \\
F-statistic & 0.944 & F-statistic & 71.58 \\
SS resid & 86.105 & SS resid & $12,003.3$ \\
Durbin Watson (DW) statistic & $80,989.2$ & DW & 1.469 \\
\hline
\end{tabular}

All continuous variables in $\ln$

Notes: all coefficients significant unless indicated (*)

IV specification Stage 1: lags, neighbors, squared values for variables: RD, units

IV specification Stage 2: lags, neighbors, squared values for variables: land value, units commercial area

significant for bare soil. Land cover in the earlier period also decreases the log odds of a current land cover staying as is, which implies that the fringe is in a state of flux. The same is true of change in residential density in an earlier period. Again, this decreases the likelihood of land cover staying in its present state. All told, changing accessibility or centrality also increases pressure for change, further underscoring the volatility of natural land covers in the urban fringe. It should be noted however while all the coefficients are significant they are not all consistently negative. This may indicate model instability.

\subsection{Simulation Results}

Given the above estimations, we use dynamic simulation for some general land cover change scenarios. This approach has shocks propagating across time (7 year lags) and space (grid cells). In all cases we observe the ratio of change between the baseline change and the scenario change. Due to the lack of symmetry between the spatial and temporal resolutions of this exercise, we expect most of the change to be driven by spatial dynamics. Because of the small cell size we do not shock individual spatial units but prefer to simulate a system wide change such as a rise in land values in time $t$ and observe how this eventually affects the likelihood of land cover change having been mediated by land use and temporal and spatial effects on the way. To this end, we report general impulse responses from scenarios even though our time lags are very coarse. This of course precludes our ability to be able to trace impulse responses dying out over time. On the other hand, the 7 year time lag here reflects the time span over which land use and land cover change take effect given the constraints of the planning system. The scenarios are as follows: 
Table 5 Probability of land cover change: MNL regression with panel data

\begin{tabular}{lllll}
\hline & \multicolumn{2}{l}{ Land cover } & & \\
\cline { 2 - 5 } & Bare soil & Forests & Orchards, plantations & Open fields \\
\hline Constant & 12.595 & 7.646 & 8.891 & 5.931 \\
Land cover - lag & -.3 .116 & -2.399 & -1.937 & -1.277 \\
Resid. density & -.074 & .025 & $-.008^{*}$ & $.010^{*}$ \\
Resid. density - lag & $.008^{*}$ & -.126 & -.045 & -.135 \\
Distance h'way & -.0005 & .0001 & -.0006 & -.0004 \\
Distance CBD & -.0002 & .0005 & .00008 & -.00005 \\
LR $\chi^{2}$ & 41,307 & & & \\
Pseudo R & 0.353 & & & \\
Log likelihood & $-33,782$ & & & \\
\hline All continuous variables in ln & & & \\
Baseline category - urbanized area & & & \\
*All coefficient significant unless indicated &
\end{tabular}

1. The effect of a $5 \%$ increase in land value in 2009: on the likelihood of land cover change from bare soil to urbanized in 2023

2. The effect of a $10 \%$ increase in residential density in 2009 on land values in 2023

3. The effect of $50 \%$ in decrease in residential density in 2016 on the ratio change in the tendency of land cover changing from fields to urbanized in 2023.

The effects of simulation 1 are graphically depicted in Fig. 5. This represents a dynamic version of the basic causal model where land values drive land use which in turns drives land cover. In this instance however we include feedback loops both temporal and spatial in the process. The output relates to the likelihood of bare soil transitioning to an urban (man-made) land cover. As can be seen, much of the change is likely to take place in the south of the metropolitan fringe with the most intensive pockets of change in the east. This reflects the pattern of urban development at the outer edge of the area suggesting creeping urbanization through spillover. Interestingly, public sector initiated urban expansion (such as in Modiin) displays less pressure for creeping development. Alternatively, it could be that initial land values in Modiin in 2009 were lower and thus the pressure for land cover change in the future is less intense.

In simulation 2 we observe the pervasive effects of increasing residential density (Fig. 6). Not only does this have a knock-on effect on land values, by changing land cover and thereby affecting land values in the next time period, but the area affected by this change is also much larger. In comparison with the first simulation where only $8.15 \%\left(50.4 \mathrm{~km}^{2}\right)$ of total fringe land cover is affected, under this simulation this share reaches $18.3 \%\left(113.2 \mathrm{~km}^{2}\right)$ Land values increase most in the established urban centers located in the metropolitan fringe. For example, Ashdod and the Arab towns of Tira and Taibe are expected to experience the most serious impacts on future land values.

Finally, simulation 3 deals with the unlikely scenario of residential density decreasing system-wide (Fig. 7). We adopt a particularly extreme scenario that 
Fig. 5 Simulation 1: the effect of a $5 \%$ increase in land value in 2009 on the land cover tendency to change from bare soil to urbanized in 2023

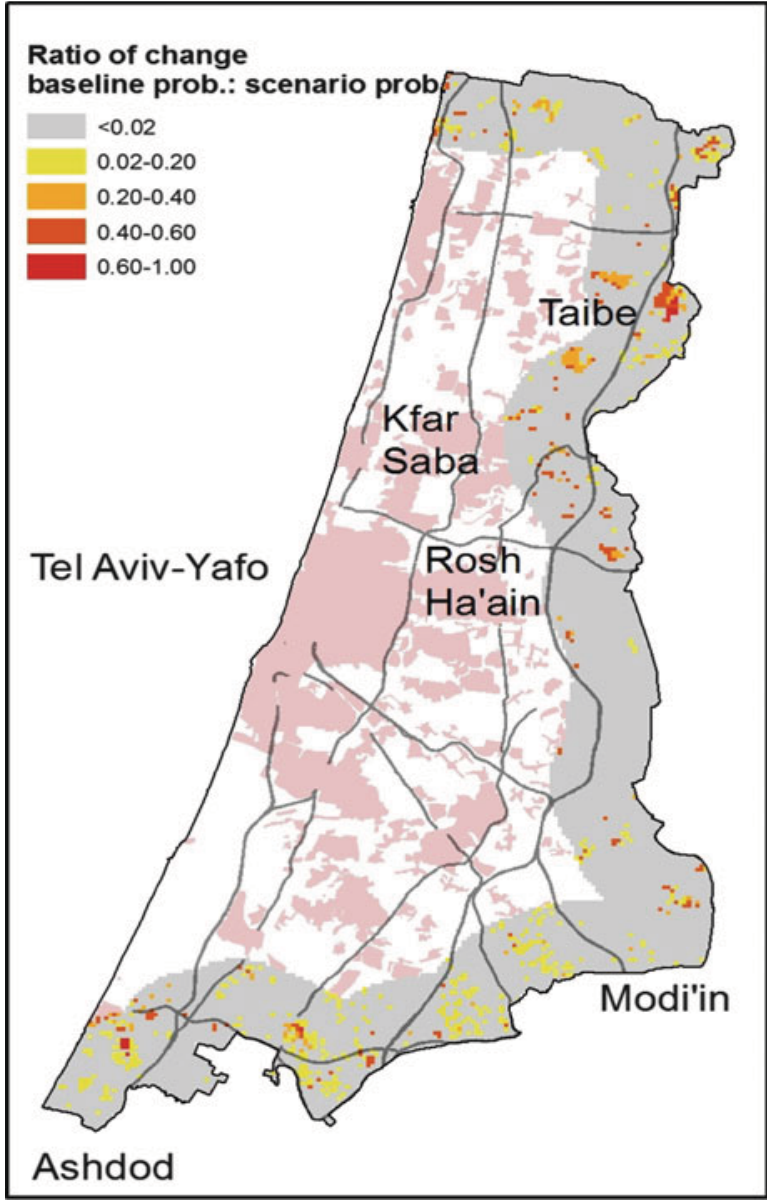

relates to the effect of a $50 \%$ decrease in residential density on the log odds of fields staying in their current state (or changing to the baseline state of urbanized area) in the next time period. This could only result from some regulatory process such as the imposition of an urban growth boundary or the strict enforcement of green belt rules in the urban fringe that would lower the relative density of development with respect to non urban fringe areas or with respect to non- designated land within the fringe.

Figure 7 shows the ratio change in the tendency of a field cover to become urbanized given the exogenous shock. As can be seen, the ratio changes are as expected mainly negative. Their total area sums to $30.4 \mathrm{~km}^{2}$. This indicates that drastically curtailing residential development will preserve field land cover. However there are still high level pressure locations where decreasing residential development still does not necessarily reduce all the pressure on field conversion. These include the suburban areas astride the metropolitan fringe such as Shoham, 
Fig. 6 Simulation 2: the effect of a $10 \%$ increase in residential density in 2009 on land values in 2023

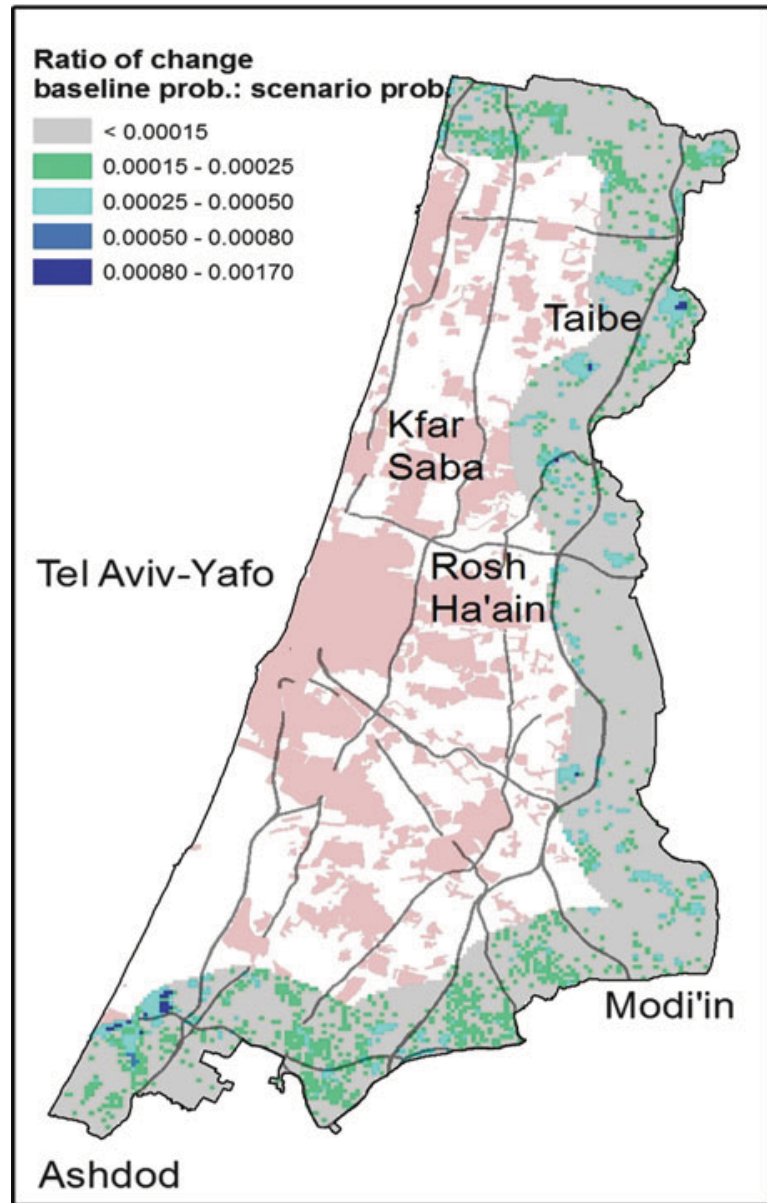

the Modiin area (see Fig. 7 inset) and the areas between the cities of Ashdod and Yavneh. Other affected cells seem to be relatively dispersed and random which seems intuitively correct. The total area of these positive values is $16.7 \mathrm{~km}^{2}$. Thus, even under a regime of strict development control we still observe points of intense development pressure close to urban centers, in high profile developments along the inner most sections of the metropolitan fringe.

\section{Conclusions}

This contribution is both methodological and substantive. In terms of method, while short of a full-blown micro-simulation, we have illustrated an approach that combines statistical estimation and impulse response simulation. Akin to economists' 
Fig. 7 The effect of a $50 \%$ decrease in residential density in 2016 on the ratio change of land cover tendency to be fields (versus the baseline category of urbanized) in 2023

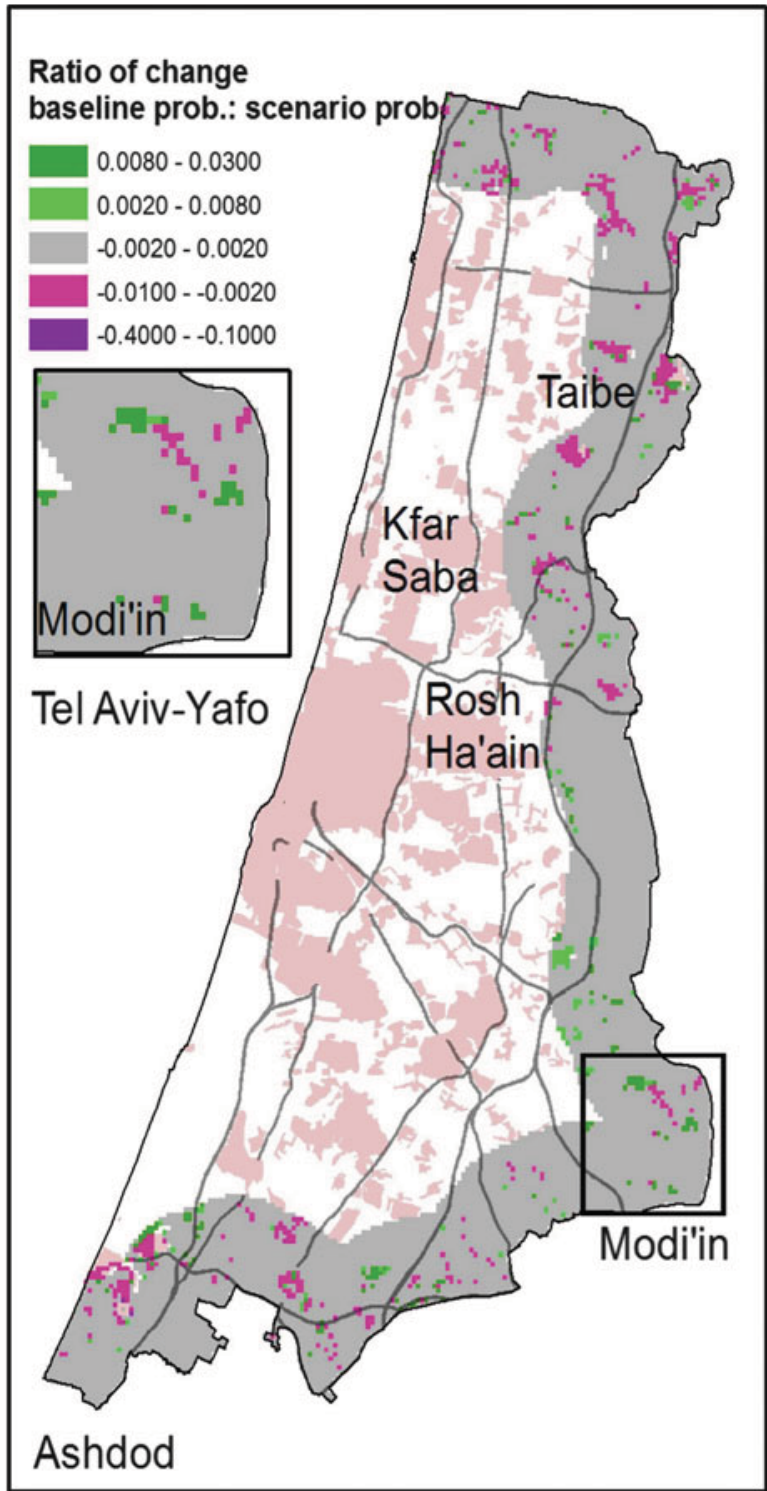

preferences for explicit representation of land markets, we model land use and land value as occurring simultaneously. Despite our recourse to UrbanSim for generating synthetic data, our simulation is not agent-based we use statistical modeling and spatial simulation to illustrate how temporal and spatial dynamics can be incorporated into the study of land use-land cover interactions. Inevitably, this necessitates addressing issues such as endogeneity and spatial dependence that are inherent in such an exercise. This has involved finding ad-hoc solutions and justifications for 
some of the shortcomings highlighted above ranging from generating the requisite data, dealing with a very short time series through to successfully identifying the effects of neighbors. Given the methodological motivation underscoring the research, these are areas that will need further attention in the future.

A second contribution has been substantive. Our results point to the precarious character of land cover in the urban fringe. Spatial and temporal feedbacks along with direct causal impacts all work to reduce the odds of contemporaneous land cover surviving in its current state into the future. Admittedly, we have chosen perhaps the most extreme empirical case available in Israel where development pressures are particularly pronounced. However, evidence from other areas also points to the existence of these pressures, albeit at a lower level of intensity.

Finally, the paper highlights the potential inherent in expanding our framework approach given a suitable analytic model. For example, when combined with an ecological or biophysical model the approach here could be extended to forecasting other aspects of environmental stress generated by metropolitan expansion. The urban impacts on vegetation or ecological dynamics or the effect of different forms of residential development of surface hydrology, are obvious examples. The policy impacts of different regulative tools both physical, such as growth boundaries and fiscal, such as development taxes, could also be assessed for their biophysical and ecological results. This is all contingent on integrating with an appropriate evaluative model. This is a research challenge that lies ahead.

Acknowledgements Thanks to Dai Xieer for assistance with the estimation.

This research is partially based on work done in the SECOA (Solutions for Environmental Contrasts in Coastal Areas) research project funded by the European Commission Seventh Framework Programme 2007-2013 under Grant Agreement No 244251.

\section{Appendix 1}

Writing Eqs. 5 and 6 in matrix form:

$$
\begin{gathered}
U_{t}=\mathrm{A}_{N} U_{t-1}+\lambda W U_{t-1}+\delta V_{t}+K X_{t}+v_{t} \\
C_{t}=\Gamma_{M} C_{t-1}+\alpha U_{t-1}+\lambda U^{*}+K X_{t}+u_{t}
\end{gathered}
$$

where: $\mathbf{A}_{\mathrm{N}}, \boldsymbol{\Gamma}_{\mathrm{M}}$ are probability transition matrices for LU and LC.

Using the time series lag operator $(\mathrm{L})$ which operates on an element, in order to produce the previous element, we solve for $\mathrm{U}_{\mathrm{t}}$ and $\mathrm{U}_{\mathrm{t}-1}$ :

$$
\begin{gathered}
(I-\boldsymbol{\Gamma} L) C_{t}=B U_{t-1}+u_{t} \\
(I-A L) U_{t}=v_{t}
\end{gathered}
$$




$$
\begin{gathered}
U_{t}=(I-\boldsymbol{A} L)^{-1} v_{t} \\
(I-\boldsymbol{A} L)^{-1}=I+\boldsymbol{A} L+\boldsymbol{A}^{2} L^{2}+\ldots \\
A^{n} \rightarrow 0 n \rightarrow \infty \\
U_{t-1}=v_{t-1} \boldsymbol{A} v_{t-2}+\boldsymbol{A}^{2} v_{t-3}+\ldots
\end{gathered}
$$

Substituting for $U_{t-1}$ in Eq. 9 and re-arranging:

$$
C_{t}=(I-\boldsymbol{\Gamma} L)^{-1} B\left(v_{t-1} \boldsymbol{A} v_{t-2}+\boldsymbol{A}^{2} v_{t-3}+\ldots\right)
$$

The inverse of the polynomial is:

$$
(I-\boldsymbol{\Gamma} L)^{-1}=I+\boldsymbol{\Gamma} L+\boldsymbol{\Gamma}^{2} L^{2}+\boldsymbol{\Gamma}^{3} L^{3}+\ldots
$$

\section{Appendix 2: Probability Estimation of Land Cover Data}

We use MNL regression for historic (2002) data to create log odds of land cover (LC) e change (from bare soil, forests, orchards, fields to built areas). Independent variables are: LC for 1995 (lc95), the most frequent LC in the neighboring cells in 19955 (neigh95), distance from 2 digit highways (2dgt), distance from 1 digit highways (1dgt), distance from metropolitan CBD (core), parks area (prk), 1995 residential land value (lv95), 1995 commercial square feet (comm95), 1995 industrial square feet (ind95), 1995 governmental square feet (gov95), 1995 number of residential units (res95). Non-significant variables are excluded and the regression re-estimated with 0.2445 misclassification rate which is equal to $51.1 \%$ accuracy. Coefficient values are as follows:

\begin{tabular}{lllllll}
\hline $\begin{array}{l}\text { Log } \\
\text { odds } \\
\text { for }\end{array}$ & Intercept & $2 \mathrm{dgt}$ & 1dgt & core & prk & Lc95[2] \\
\hline $2 / 6$ & 1.06300627 & 0.02128593 & -0.0212716 & -0.0000239 & -0.000018435 & 1.39784825 \\
$3 / 6$ & 1.6741873 & 0.0547843 & -0.0546622 & -0.000070779 & -0.0001232 & 0.00525623 \\
$4 / 6$ & 0.01532415 & 0.01373619 & -0.0138219 & -0.0000009686 & -0.0001346 & -0.8704572 \\
$5 / 6$ & 0.11464507 & 0.02095321 & -0.021061 & -0.0000082171 & -0.000061941 & -0.0847443 \\
\hline \multicolumn{7}{c}{} \\
& & & & & \\
\hline Log odds for & Lc95[3] & Lc95[4] & Lc95[5] & neigh95[2] & neigh95[3] \\
\hline $2 / 6$ & 1.3162059 & -0.5565036 & -0.9872424 & 0.81029937 & 0.24571899 \\
$3 / 6$ & 2.21462143 & 0.91567457 & -0.8596639 & -0.1341568 & 1.35462331 \\
$4 / 6$ & -0.6881597 & 3.05639013 & -0.1230151 & -0.2588099 & -1.0215386 \\
$5 / 6$ & -1.5210677 & 0.23063331 & 2.64963015 & -0.0652665 & -1.1603799 \\
\hline
\end{tabular}




\begin{tabular}{lllll}
\hline Log odds for & neigh95[4] & neigh95[5] & lv95 & res95 \\
\hline $2 / 6$ & -0.0369579 & -0.4688555 & -0.0000000056334 & -0.0053964 \\
$3 / 6$ & 0.33465383 & -0.9959705 & -0.0000038221 & -0.0217897 \\
$4 / 6$ & 1.39302637 & 0.11419243 & -0.0000018486 & -0.0196984 \\
$5 / 6$ & 0.19326558 & 1.08702141 & -0.0000033074 & -0.016155 \\
\hline
\end{tabular}

These parameters are then tested by using the 2002 LC data and 2002 land use model outputs as independent variables. The predictions of this regression generate $53.48 \%$ accuracy when compared with actual 2009 LC data. After each round, the outputs of the previous round become the $t-l$ values for a new round, i.e. LC value calculated in round $t$ becomes LC data for round $t+1$. This is repeated for each time period with time lags of $\mathrm{t}=7$.

\section{References}

Alberti, M. (2005). The effects of urban patterns on ecosystem function. International Regional Science Review, 28(2), 168-192.

Alberti, M. (2008). Advances in urban ecology: Integrating human and ecological processes in urban ecosystems. New York: Springer.

Alberti, M., \& Waddell, P. (2000). An integrated urban development and ecological simulation model. Integrated Assessment, 1, 215-227.

Baltagi, B. H. (2008). Econometric analysis of panel data. London: Wiley.

Felsenstein, D., \& Ashbel, E. (2010). Simultaneous modeling of developer behavior and land prices in UrbanSim. Journal of Transportation and Land Use, 3(2), 107-127.

Felsenstein, D., Ashbel, E., \& Ben-Nun, A. (2007). Microsimulation of metropolitan employment deconcentration. In E. Koomen, J. Stillwell, A. Bakema, \& H. J. Scholten (Eds.), Modelling land use change: Progress and applications, volume 90 of GeoJournal library (pp. 199-218). Netherlands: Springer.

Haan, P., \& Uhlendorff, A. (2006). Estimation of multinomial logit models with unobserved heterogeneity using maximum simulated likelihood. The STATA Journal, 6(2), 229-245.

Hepinstall, J. A., Alberti, M., \& Marzluff, J. M. (2008). Predicting land cover change and avian community responses in rapidly urbanizing environments. Landscape Ecology, 23, 1257-1276.

Ihlanfeldt, K. R. (2007). The effect of land use regulation on housing and land prices. Journal of Urban Economics, 61, 420-435.

Irwin, E. G. (2010). New direction for urban economic models of land use change: Incorporating spatial dynamics and heterogeneity. Journal of Regional Science, 50(1), 65-91.

Irwin, E., Jayaprakash, C., \& Munroe, D. K. (2009). Towards a comprehensive framework for modeling urban spatial dynamics. Landscape Ecology, 24, 1223-1236.

Lee, M. J. (2013). Practical panel conditional logit estimators for binary, Ordered discrete and multinomial responses. The Oxford handbook of panel data econometrics. Oxford University Press, Oxford, UK.

Levin, N., Harari-Kremer R., \& Carmel, Y. (2011). Remote sensing of Israel's natural habitats, Unpublished Report for the Israeli Nature and Parks Authority, Jerusalem.

Lopez, A., Bocco, G., Mendoza, M., \& Duhau, E. (2001). Predicting land-cover and land-use change in the urban fringe: A case in Morelia city, Mexico. Landscape and Urban Planning, $55,271-285$. 
Mayer, C. J., \& Somerville, C. T. (2000). Land use regulation and new construction. Regional Science and Urban Economics, 30, 639-662.

Neyman, J., \& Scott, E. L. (1948). Consistent estimates based on partially consistent observations. Econometrica, 16, 1-32.

Parker, D. C., Manson, S. M., Janssen, M. A., Hoffman, M., \& Deadman, P. (2003). Multi-agent systems for the simulation of land-use and land-cover change: A review. Annals of the Association of American Geographers, 93, 314-337.

Ravetz, J., Fertner, C., \& Nielsen, T. (2013). The dynamics of peri-urbanization. In K. Nilsson, S. Pauleit, S. Bell, C. Aalbers, \& T. Nielsen (Eds.), Peri-urban futures: Scenarios and models of land use change in Europe (pp. 13-44). Heidelberg: Springer.

van Schrojenstein Lantman, J., Verburg, P., Bregt, A., \& Geertman, S. (2011). Core principles and concepts in land use modelling: A literature review. In E. Koomen \& J. Borsboom-van Beurden (Eds.), Land use modelling in planning practice (pp. 35-57). Dordrecht: Springer.

Verburg, P. (2006). Simulating feedbacks in land use and land cover change models. Landscape Ecology, 21, 1171-1183.

Verburg, P. H., Schot, P. P., Dijst, M. J., \& Veldkamp, A. (2004). Land use change modeling: Current practice and research priorities. GeoJournal, 61, 309-324.

Waddell, P., \& Ulfarson, G. F. (2003). Introduction to urban simulation: Design and development of operational models. In P. Stopher, K. Button, K. Kingsley, \& D. Hensher (Eds.), Handbook in transport, vol 5. Transport geography and spatial systems. New York: Pergamon Press. 